\title{
Rapid Processing of Photographic Plates for Routine Spectrographic Analysis '.
}

\author{
by \\ II. B. Fincent and I. A. Sawyer, \\ Eniversty of Michipali Ann drler, Melugun, U SA \\ With 3 figures in the text.
}

(Eingegangen am 1ז. Juni 1939.)

Since the casting of alloy iron is usually a continuous rather than a batch process, the problem of composition control resolves itself into a control of the drifts in the concentration of the several alloying constituents in the molten iron in the furnace or cupola. If the drifts are to be maintained within narrow limits of tolerance, the analysis system used must meet several requirements 'The accuracy of the analysis must, of course, be adequate; specifically, the uncertainty must be substantially less then the permissible variation in content. In addition, it is of vital importance that the elapsed time between the pouring of a sample of the iron and the posting of the analysis results should be made as brief as possible; otherwise, a control of drifts is not provided and an inspection analysis only results.

For some years, the authors have been interested in the application of the spectrograph to routine control problems in iron and steel. Papers have been published elsewhere ${ }^{2 \cdot 3}$ on the development of a spectrographic method of analysis and its installation at the plant of the Campbell, Wyant and Cannon Foundry Company, Muskegon, Michigan. The procedure permits the analysis of a sample of cast iron for chromium, copper, manganese, molybdenum, nickel and silicon in seven minutes elapsed time, while the accuracy exceeds that of the routine chemical wet methods previously used.

In the analysis procedure, spectra are recorded on a photographic plate on glass sufficiently thin to accept without fracture the curvature imposed by the spectrograph. The plate is processed, and, since efforts to measure densities on wet plates have proved uniformly unsatisfactory, it is dried before the reaclings are taken. Since the processing and drying of the photographir plate was ini. tially, and still remains, the most protracted operation of the allalysis schedule. the problem of reducing the time required has been given considerablr attention. It is thought that the technique developed may be of interest to -pectroscopists and to others for whom rapid plate processing is urgent. Detaik of the procedure are presented below

While the processing of any photographic plate may he hastenced, it is necessary to control the emulsion thickness much more cartully than is customary for stock plates if a uniform time schedule is to be maintained. All of the

1 The developments reported here ucre carried out in the Department of Physies in connection with industrial projects sponsored through the Department of Fingineering Research.

3 Vincent, H. B. and K. A. Sauyer: J.A.P. 8, 163-173 (1937).

3 Vincent, H. B., R. A. Sactyer and A.M. Sampom: Mletals and Alloys, Fet, 1938. 
plates used for routine analysis are special in that the thickness of the dry emulsion is held very close to one one-thousandth of an inch. For this emulsion thickness, in the neighbourhood of $3000 \mathrm{~A}$, the density is proportional to the logarithm of the exposure for densities between 0,2 and 1,2 . If higher densities are mandatory, a thicker emulsion must be used and the corresponding increase in processing time accepted. A further requirement of the emulsion is very strong adhesion to the glass to withstand without frilling the sudden changes in concentration between solution and wash.

The plate used most extensively for analysis work has been a special Cramer Contrast plate manufactured by the G. Cramer Dry Plate Company, St. Louis,

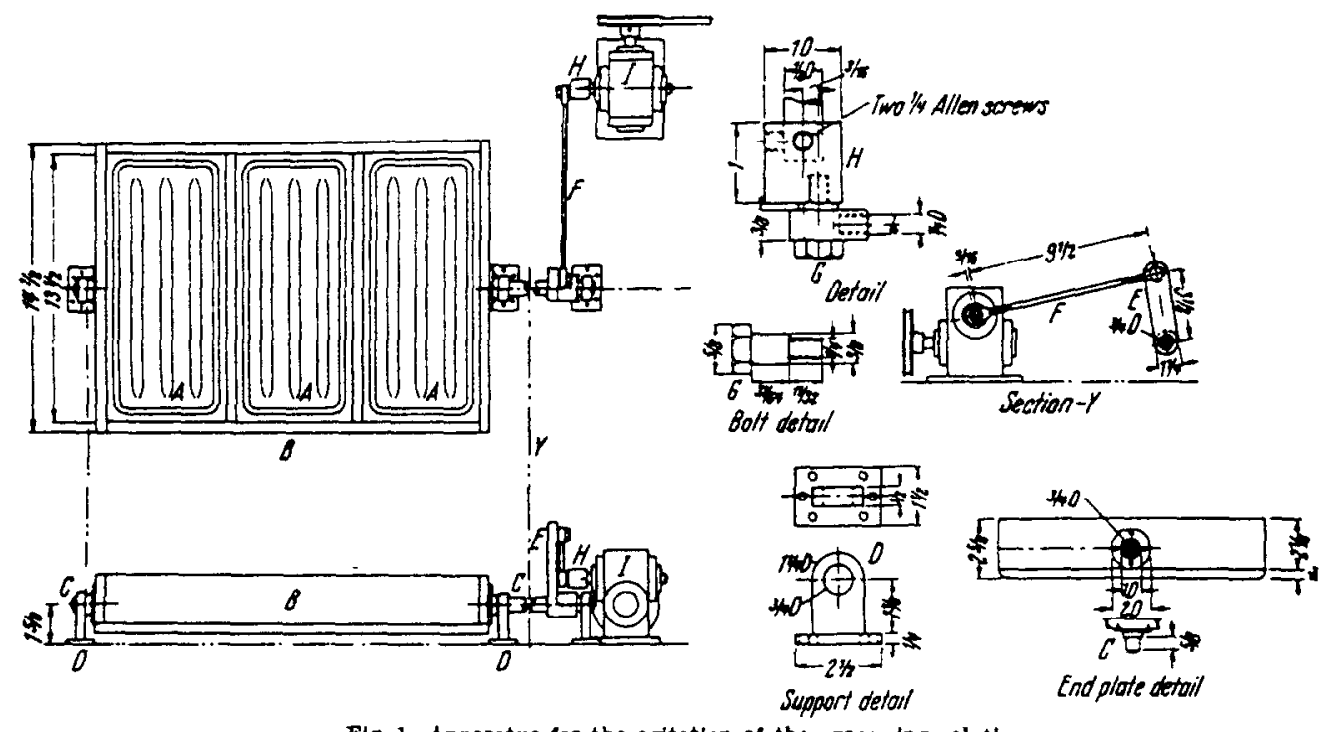

Fig. 1. Apparatus for the agitation of the procesing solutions.

Mo. This plate is processed and dried in laboratory routine in an elapsed time of four to five minutes. The Eastman Kodak Company has recently developed a special Contrast Process Plate which requires about three minutes for processing and drying ${ }^{1}$. These plates both have fine grain and high contrast. The processing described below yields a gamma of about unity.

Not only the reducing solution employed, but also the method of its appli. cation, are important if brief and satisfactory development is to be realized. If the time is quite short, of the order of one minute or less, uniform development is hardly to be anticipated with random or no agitation of the solution; under such conditions, Eberhard effect may be quite troublesome. Uniform positive agitation not only minimizes these difficulties, but has the desirable effect of hastening all phases of the processing, developing, hardening and fixing.

While the apparatus for agitation of the solutions should be adapted to the individual requirements of the laboratory, a satisfactory unit arrangement is shown in Fig. 1. Glass trays A are carried in a wooden frame B attached to shafts $C$ supported by bearings $D$. The trays are oscillated about the axis $C$ by means of arm $E$ and rod $F$ engaging the decentered pin $G$ carried on the

1 This plate is, at present, designated as No 385 . 
coupling $H$ which is attached to the lower speed shaft of the worm gear unit $J$. The gear reduction unit is driven, through a belt, by a small electric motor $\mathrm{K}$. The frequency of the oscillation should be so adjusted that a wave of the solution travels uniformly from one end of the tray to the other and no nodal regions appear. The optimum speed of operation depends on the size of the tray and on the depth of the solution, but should approximate one oscillation per second. Yor ease of cleaning, glass trays appear preferable to those made from plastics ${ }^{1}$. The location of the apparatus at the edge of the sink eliminates the dripping of solution on the bench.

Some relaxation of the completeness of washing is permissible since the deterioration with storage likely to result is of small importance for routine

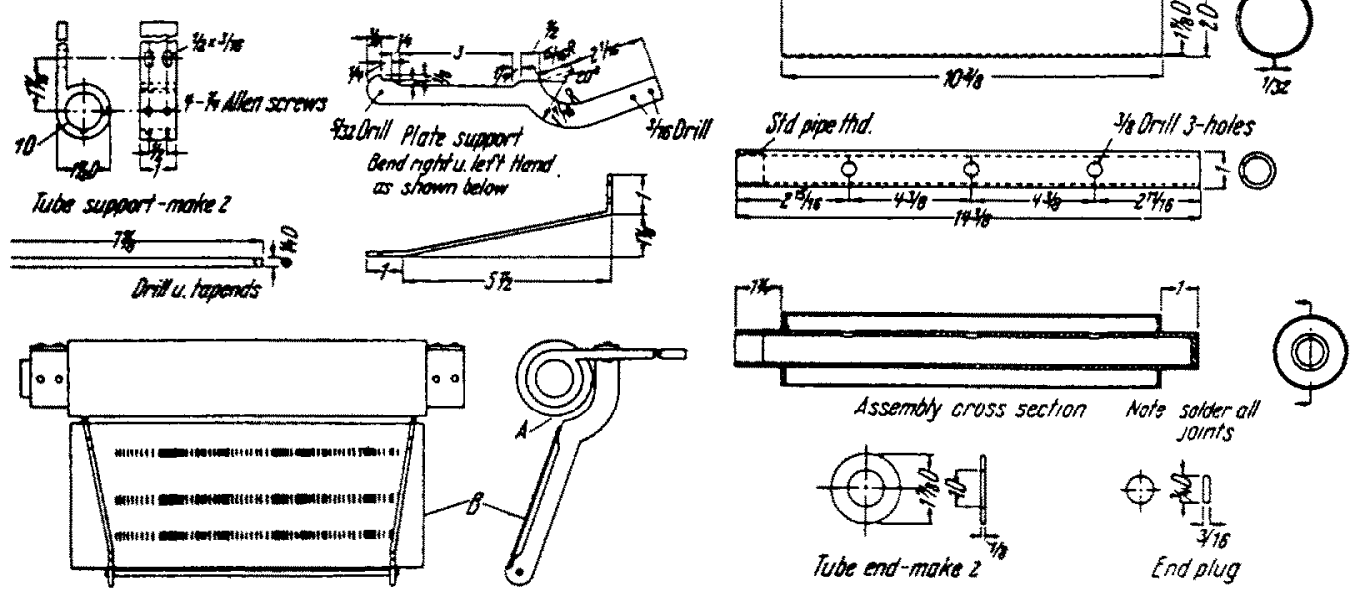

Fig. 2. The plate washer.

procedure where plates are stored, at most, only briefly. This relaxation, however, must not be carried to a point where sufficient hypo remains in the emulsion to affect appreciably the density measurements. Rapid and satisfactory washing has been attained with the apparatus shown in Fig. 2. A flat stream of water issuing under pressure from the orifice $A$ strikes the plate $B$ nearly tangentially at its upper edge and flows downward over the emulsion at high speed. As shown in the figure, the stream of water should be as wide as the longer dimension of the plate. The pressure should be adjusted to as high a value as may be used without hazard of detaching the emulsion from the glass.

It has been found that photographic plates may be dried satisfactorily and expeditiously with the device illustrated in Fig. 3. The plate is placed, emulsion side upward, in the frame $\mathrm{B}$ carried by the transite box $\mathrm{C}$, which, in order to make its appearance more attractive, is usually covered with bakelite or metal panels. Infrared radiation is emitted by the coil $\mathrm{D}$, of nichrome or other suitable resistance wire, which is energized from the lines LL. A centre tap on the resistor and the switch $\mathrm{S}$ provide a higher and a lower coil temperature. The higher

1 The size shown in the illustration may be obtained from the Sneath Glass Co., Hartford City, Ind. under the designation \# $\mathrm{C}-097$. The tray has a ribbed bottom which facilitates tho removal of plates. 
power is nsed brefly at the start of the process to clevate the enulsion rapidly to the drying temprature. Air from the rom is driven rapidly across the emulaion by the fan F. a relaterely fechle current of air is carried through the hox by the small holes $\mathrm{HH}$ to remore the moivture evapnrated from the glass surfice of the plate The depression G farlitute the remoral of the dried plate from the iryer.

For plates four inches wite by ten to twolve inches long, the lower power input should be abent 4.00 watts: the highor posure is of course. four times the lower. Fle ghass. While transmitting minsent ratiation which is absorbed by the water m the emulsien, also ahoorhs the inger wa velungth rass which, together with ome contribution from consertion, ratiss its temprature during the

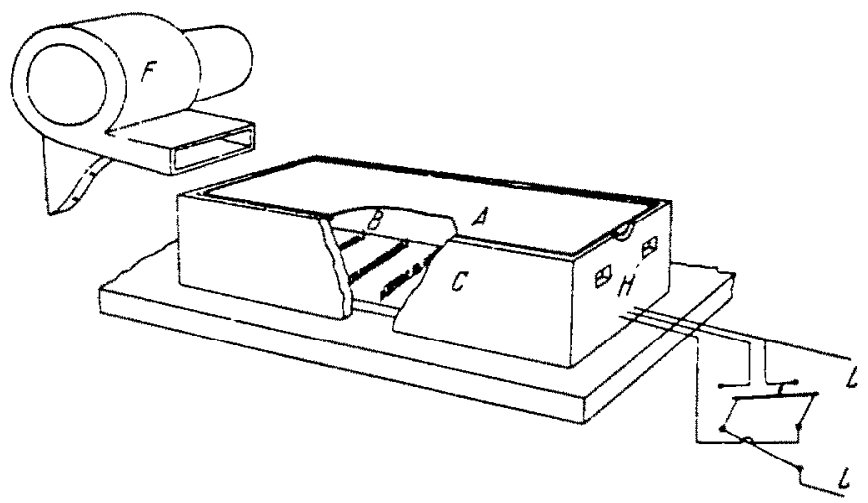

Fix. 3, The plate aryer.

drying If the power mentioned above is used, the plates must he removed promptly when dry or the glass will probably erack

The chore of a developing solution inwolves several considerations A single solution developer is obviously preferable for routine work since the errors likely to oceur in compounding under the pressure of maintaining an operating scherluke are eliminated. The solution must be clean-working and have reasonable kepping qualities, although in laboratorics using sereral dozen plates per day storage over long periods is unnecessary. Ahow all, the reduction potential must be high so that development proeseds rapielly.

To meet these refuirements, the anthors have used a hydroquinone-caustic soda dereloper of the ton of the Eastman DS and similar formulas. The caustic serhe content of the concentrition or both are arljusters to sield a minimum development time without aperectable discoloration of the unexposed prortions

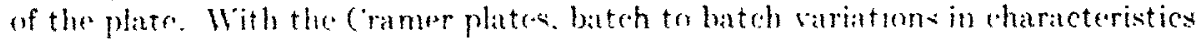
have necessitated oreasional rearljustment of the developer formula; the limited exprienes with the Fastman 34.7 plate indicates better uniformity and less tendency towand stain A trpical devoloping formula is given below.

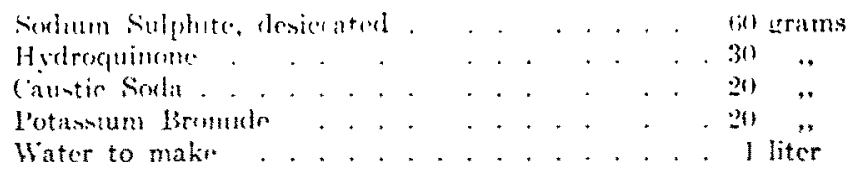

Derrlope for 30 seronds at 70$)^{\circ} \mathrm{F}$. 
Unquestionably. hisher development opeeds can be realized with reilurers such as pyrocatechin or catechol. However. for tuntiurn malt it ippears

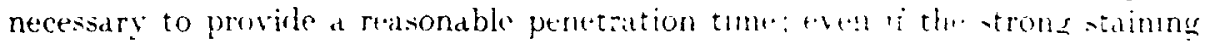

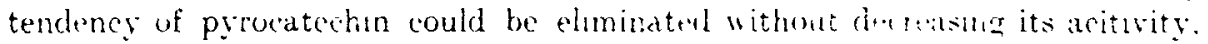

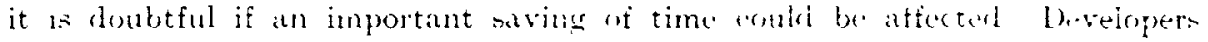
rontaining sodium or potas-ium carbuhite as alkahe and e-perally tho-c usmer glyoin as reducins agent, have superior beeping qualitio.n. but with all sich formulas tested, the derelopment was prolonged. It is thmatht that metol shows more variation in contrast with degree of levelopment, than does hylro. quinone, - an undesirable characteristic since. for routine photonetric work, constant or nearly constant contrast is arlvantageou;.

'To permit the application of relatively high temperatures in drying. the plates are hardened in a twenty per cent chrome alum solution Formalin. while quite effective, is undesirable since its fumes are disagreeable and slightly toxic. The prehardening of the plates in manufacture may be urried to a point where further handening during processing is not necesisary, but, since the penetration of the solutions is delayed by the prehardening, the processing time is likely to be extended.

In routine analysis work, where density measurements are to be effected immediately and where ability to withstand storage over long periods without deterioration is unimportant, the plate may be removed from the fixing bath as soon as it is cleared. The clearing time is dependent on two factors, the thickness of the emulsion and the activity of the bath. Emulsion thirkness has been discussed above. The formula for a fixing solution which has been found to be quite satisfactory is given below.

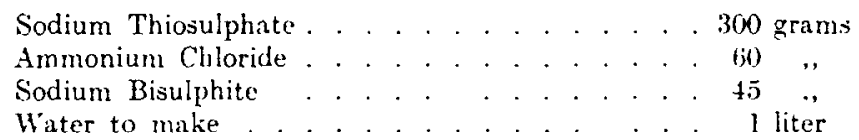

Some acidulation of the fixing bath is desirable since the chrome alum carried over from the hardening precipitates sulphur from a neutral solution. However, the addition of acid decreases the activity so such additions should be kept as small as feasible. Other acidulators such as potassium metabinalphite or acetic acid with sodium sulphite may be used quite satisfactorily.

It appears desirable to mention at this point a matter which, while quite obvions, is sometimes overlooked the cost of the solutions as very moderate and the use of fresh baths of tandard activity promotes unformity in processing "The ue of solutions to complete exhaustion is never justified, and, in. deed, they should be repla. ced at the first evidence of fatigue.

\begin{tabular}{|c|c|c|}
\hline Promen & \multicolumn{2}{|c|}{ 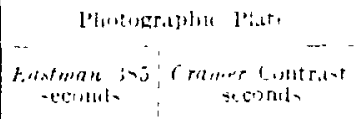 } \\
\hline 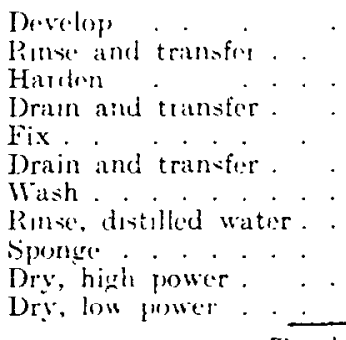 & $\begin{array}{r}311 \\
10 \\
1.5 \\
.7 \\
2.7 \\
.7 \\
311 \\
10 \\
111 \\
1.5 \\
2.7 \\
\end{array}$ & $\begin{array}{r}310 \\
111 \\
15 \\
5 \\
4.5 \\
5 \\
30 \\
10 \\
10 \\
10 \\
6.5 \\
7.5\end{array}$ \\
\hline Total & Iso & 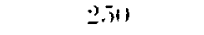 \\
\hline
\end{tabular}


The processing schedule for plates used in routine procedure is given below. Some variation from plate to plate in the fixing and drying speed is to be anticipated; the times quoted are average. The sponging mentioned in the following table involves the remoral of surface moisture from the plate by means of a viscose sponge dampened with distilled water.

The technique described above is in current use at plants of the Campbell, Wyant and Cannon Foundry Company, Muskegon, Mich., the Great Lakes Steel Corporation, Ecorse, Mich., the Bethlehem Steel Company, Lackawanna, New York, and the Ford Motor Company, Dearborn, Mich. The times cited are taken from the Ford laboratory schedule. Experience has shown that the uniformity of the processing satisfies adequately the exacting requirements of routine spectrographic control analysis. The procedure outlined and adaptations thereof are recommended for consideration where rapid processing of photographic materials is advantageous. 